\title{
SWOPT - the South-West Organisation for Psychiatric Training
}

There are major challenges in providing training for psychiatrists in the modern National Health Service (NHS). Senior house officer and specialist registrar training has been reorganised to focus on core skills and competencies, and is monitored through educational supervision and the Record of In-Training Assessment (RITA) process. For consultants, the development of appraisal and revalidation are linked to formalised approaches to continuing professional development and personal development (Royal College of Psychiatrists, 2001). Increasingly, training is self-directed and psychiatrists have to effectively evaluate and plan for their individual educational needs. They must be able to access good quality, structured training, to develop and maintain a range of specific and generic skills.

In the late 1990s, specialist registrar training in the south-west region tended to be organised locally on an ad hoc, personal basis. In keeping with other schemes, two 'research' sessions were awarded, but little thought given to the resourcing and management of research training, and supervision. In particular, there was a lack of opportunities for local generic skills training, so that trainees had to travel extensively, to access expensive courses, of sometimes dubious quality. The South-West Organisation for Psychiatric Training (SWOPT) programme was developed to provide an integrated programme for generic skills training, pooling training resources across the region. This would facilitate a systematic appraisal of the training needs for each specialist registrar through the RITA process.

\section{SWOPT - providing quality training, locally}

The training modules provided through SWOPT can be seen in Table 1.

Each module is organised by a consultant/specialist registrar team, co-opting specialist trainers as appropriate. Training events occur throughout the region to improve access and opportunity. In keeping with best practice (Petersen, 1999; Wilkes \& Bligh, 1999), all modules have been evaluated formally, feedback being sought on various aspects of the quality of teaching (including participation), as well as the venue and refreshments. We have also collected qualitative data about the 'best' and 'least satisfactory' aspects of each course, together with suggestions for development of course content and new modules.

SWOPT was set up with a Deanery grant and through educational grants from drug companies sponsoring specific modules, and contributing to the biannual meeting. Initially, each specialist registrar appointed regionally paid a small, one-off registration to SWOPT, and subsequently a small annual fee. Consultants and other professionals are charged a fee per course.

\section{The biannual south-west region conference}

In addition to the modular training programme, each year SWOPT delivers two conferences developed alternately by Bristol and Exeter University Departments of Mental Health. Recent conferences have focused on in-patient services and primary care. Specialist registrars are encouraged to present posters setting out their research plans on joining the rotation, and subsequently the outcome of their research.

\section{Progress to date}

Feedback scores average 'good' or 'excellent' across all domains on quality of training. In 2002 we instituted an annual SWOPT 'away day', for module organisers to meet, in the company of professional educationalists, to review the progress of each module and develop the programme. Increasing numbers of consultants, career grade doctors and other professionals are enrolling for courses. Some trainees have expressed concern about limitations on their freedom to self-select training,

Table 1. The South-West Organisation for Psychiatric Training modules

\begin{tabular}{|c|c|c|c|}
\hline & $2000 / 1$ & $2001 / 2$ & (Planned for 2002/3) \\
\hline Mental health services management & Split 6-day course & Split 7-day course & Split 7-day course \\
\hline Critical appraisal & 3-day course & 2-day course (Bristol and Exeter) & 2-day course (Bristol and Exeter) \\
\hline Personal development & & 1-day course (Bristol and Exeter) & 1-day course \\
\hline Appraisal and supervision & 1-day course & 1-day course & 1-day course \\
\hline Litigation in the National Health Service & & 1-day course & 1-day course \\
\hline Regional conference & 2 full day conferences & 2 full day conferences & 2 full day conferences \\
\hline
\end{tabular}


F

education \& training although in reality the SWOPT courses would not have existed without this initiative. The biannual conferences have attracted over 150 delegates to programmes with high quality, international speakers.

\section{The future}

We are engaged in a regional review of generic skills training, with other providers. The workload has exceeded administrative capacity, and we plan to recruit secretarial support for the 3-day/week administrator. New initiatives include the development of a series of research training programmes and modules on psychiatric ethics and curriculum vitae/interview training. The team leadership course is being integrated with a regional university foundation programme, to allow possible passage towards certificates/diploma/Masters Degree in interdisciplinary mental health. We hope to develop a website for SWOPT to facilitate access to courses through the region.

\section{Conclusion}

If we are to meet the challenges of training and continuing professional development in the modern NHS, we will need to have better organised and coordinated training of our workforce. The Royal College of Psychiatrists is currently working on the identification of core competencies in various psychiatric fields, and we agree with Cottrell (2003) that this process is likely to have far reaching implications for what psychiatrists need to learn

and how they will be taught. We commend the SWOPT formula, which has helped to coordinate and improve the quality of psychiatric training available in our region. A programme such as this, integrating research with generic skills training, is a model which could potentially be applied more broadly.

\section{Acknowledgements}

The authors would like to thank all the module organisers and teachers for their extensive contributions to the SWOPT programme. We are grateful to Tom Edwards and Stephen Pearson for helping to prepare the paper, and thank Julie Bundy for her work on the manuscript.

\section{References}

COTTRELL, D. (2003) Raising the standards of educational evaluation and research. Psychiatric Bulletin, 27,1-2

PETERSEN, S. (1999) Time for evidence based medical education. BMJ, 318 1223-1224.

THE ROYAL COLLEGE OF

PSYCHIATRISTS (2001) Good

*Rob Macpherson Consultant Psychiatrist, Director, SWOPT Programme, Wotton Lawn, Horton Road, Gloucester, GL13WL, Glyn Harrison Professor of Community Psychiatry, Division of Psychiatry, University of Bristol, Adrian James Consultant Forensic Psychiatrist, Butler Clinic, Langdon Hospital, Dawlish, Devon, Martin Curtice Specialist Registrar in Psychiatry, Cossham Hospital, Bristol, Pat McPhee Events Coordinator, SWOPT, Division of Psychiatry, University of Bristol 